\title{
A Cerebral Malaria Simulating an Epileptic Seizure
}

\section{Savadogo Mamoudou*}

Department of Infectious Diseases of Yalgado Ouedraogo University Hospital, Burkina Faso, Africa

${ }^{*}$ Corresponding author: Savadogo Mamoudou, Department of Infectious Diseases of Yalgado Ouedraogo University Hospital, Burkina Faso, Africa, Tel: 0022670259154; E-mail: savadoma@gmail.com

Received: Feb 13, 2016; Accepted: Feb 18, 2016; Published: Feb 22, 2016

Copyright: (C) 2016 Mamoudou S. This is an open-access article distributed under the terms of the Creative Commons Attribution License, which permits unrestricted use, distribution, and reproduction in any medium, provided the original author and source are credited.

\section{Abstract}

The occurrence of tonic clonic convulsion in an irregularly monitored epileptic patient may pose a problem of differential diagnosis with other convulsant pathologies such as cerebral malaria. We are reporting a case of cerebral malaria that occurred in an epileptic patient whose seizures had been taken as a status epilepticus, the consequence of which was a delay diagnosis of malaria. The objective is to contribute to better monitoring of people with epilepsy. This is about a young 27-year-oldepileptic person who had stopped his treatment and was admitted to hospital on August 12th 2015 for subintrant tonic clonic seizures associated with loss of consciousness. The examination upon admission revealed a general poor condition with a clouded consciousness, colored anicteric conjunctiva, an infectious syndrome with a temperature at $39^{\circ} \mathrm{C}$, severe dehydration, Heart Function at 137 beats/min, Blood Pressure at 140/90 $\mathrm{mmHg}$, claret red urine (hemoglobinuria). Bicarbonates were reduced to $15 \mathrm{mmol} / \mathrm{l}$ (acidosis), the creatinine $154.6 \mathrm{mmol} / \mathrm{l}$ (functional renal failure) and thick smear came back positive with a parasite density at 819 parasites $/ \mathrm{ml}$. Under treatment with artemether, Depakine and amlodipine, the outcome was favorable and he was discharged/released from hospital on August 18th 2015.

The occurrence of subintrant tonic-clonic seizures in an epileptic patient must lead to search and quickly eliminate an infectious cause of convulsions such as cerebral malaria.

Keywords Epilepsy; Cerebral malaria; Tonic clonic seizures

\section{Introduction}

Epilepsy is one of the most common neurological diseases [1]. In Sub-Saharan African countries where malaria prevalence is high, the occurrence of seizures in an irregularly monitored epileptic, may delay diagnosis of associated neuro malaria. We are reporting a case of cerebral malaria that occurred in a patient with epilepsy and whose seizures had been taken as manifestations of status epilepticus. The objective is to contribute to better monitoring of people with epilepsy.

\section{Observation}

A 27-year-old patient, known epileptic and irregularly monitored since the age of three years. He was out of its antiepileptic treatment. He was admitted on August 12th 2015 for tonic clonic seizures associated with loss of consciousness. These subintrant convulsions (about a crisis every 30 minutes), taken at first for its seizure, led him to consult a health facility where he might have received care without success. Because of the persistence of crises, he was referred to YO University Hospital for better treatment. The examination upon admission revealed poor general condition with a clouded consciousness, colored anicteric conjunctiva, an infectious syndrome with a temperature at $39^{\circ} \mathrm{C}$, moderate dehydration, a heart rate of 137 beats/min, high blood pressure at $140 / 90 \mathrm{mmHg}$, haemoglobinuric urine. The thick smear came back positive, bicarbonates were lowered to $15 \mathrm{mmol} / \mathrm{L}$, serum creatinine increased to $154.6 \mathrm{mmol} / \mathrm{l}$. The diagnosis of severe malaria was selected. Under treatment based on artemether, PERFALGAN and bicarbonate infusion, the outcome was favourable and he was released from hospital on August 18th 2015.

\section{Discussion}

Malaria is a major and very prevalent parasitic disease in sub-Saharan Africa. The neurological form is the most severe complication with a high mortality rate [2]. Its most common neurological manifestations are convulsions and loss of consciousness which may also be found during a seizure. The prevalence of epilepsy is higher in Burkina Faso than the world average [1]. Brain infections are considered to be the cause of the high prevalence of epilepsy in developing countries [3]. Next to cysticercosis and toxoplasmosis which seem to be the dominant etiology in our context, we have cerebral malaria [3]that we need to recognize and search in the event of an epileptiform crisis. Epilepsy mainly concerns young male people, and mostly manifests in its generalized tonic clonic form $[3,4]$ and these manifestations may delay the diagnosis of cerebral malaria. Hence the necessity of a systematic search of an associated infectious etiology in presence of a subintrant tonic clonic crisis of a known epileptic patient. 


\section{Conclusion}

The occurrence of subintrant convulsive seizures in an epileptic patient should lead the clinician to systematically look for other causes of seizures such as cerebral malaria. To do this, health workers should be consequently trained.

\section{References}

1. Napon Christian, Yacouba Tamboura, Jean Kabore (2009) Epilepsy subjects over 14 years at the University Hospital of Ouagadougou (Burkina Faso) Epilepsy 21: 93-7.
2. Edgard Brice Ngoungou, Euloge Ibinga, Maryvonne Kombila, Pierre-Marie Preux (2010) News on cerebral malaria. Summary JNLF Lyon.

3. Krishnamoorthy ES, Satischchandra P, Sander JW Research in epilepsy: development priorities for developing nations. Epilepsia 44: 5-8.

4. Raveloson NE, Rakotonirina HM, Rakotoarivony ST, Andrianjatovo JJ, Randriamiarana JM (2009) Features status epilepticus in adults (about 66 cases observed in the ATU/R Service CHU.A/Joseph Raseta Befelatanana). Journal of Anesthesiology and Emergency Medicine (May-June) 1: 7-10. 